\title{
CRATERS PRODUCED ON METALS BY SINGLE ION IMPACTS*
}

R. C. Birtcher ${ }^{1}$ and S. E. Donnelly ${ }^{2}$

${ }^{1}$ Materials Science Division

Argonne National Laboratory

9700 S. Cass Ave.

Argonne, IL 60439

${ }^{2}$ Joule Physics Laboratory

University of Salford

Manchester M5 4WT

United Kingdom

November 1998

The submitted manuscript has
been created by the University of
Chicago as Operator of Argonne
National Laboratory (Argonne'
under Contract No. W-31-109.
ENG-38 with the U.S. Department
of Energy. The U.S. Government
retains for itself, and others
acting on its behalf, a paid-up,
non exclusive, irrevocable
worldwide license in said article
to reproduce, prepare derivative
works, distribute copies to the
public, and perform publicly and
display publicly, by or on behalit
of the Govemment.

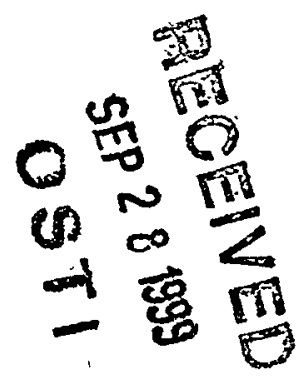

Submitted to the Materials Research Society, November 30 -December 4, 1998, Boston, MA.

*Work supported by the U. S. Department of Energy, Office of Basic Energy Sciences, under Contract W-31-109-Eng-38 at Argonne National Laboratory and a collaborative research grant number 910670 from NATO. 


\section{DISCLAIMER}

This report was prepared as an account of work sponsored by an agency of the United States Government. Neither the United States Government nor any agency thereof, nor any of their employees, make any warranty, express or implied, or assumes any legal liability or responsibility for the accuracy, completeness, or usefulness of any information, apparatus, product, or process disclosed, or represents that its use would not infringe privately owned rights. Reference herein to any specific commercial product, process, or service by trade name, trademark, manufacturer, or otherwise does not necessarily constitute or imply its endorsement, recommendation, or favoring by the United States Government or any agency thereof. The views and opinions of authors expressed herein do not necessarily state or reflect those of the United States Government or any agency thereof. 


\section{DISCLAIMER}

Portions of this document may be illegible in electronic image products. Images are produced from the best available original document. 


\section{CRATERS PRODUCED ON METALS BY SINGLE ION IMPACTS}

R. C. Birtcher, Materials Science Division, Argonne National Laboratory, Argonne, IL. 60439, USA; and S. E. Donnelly, Joule Physics Laboratory, Science Research Institute, University of Salford, Salford M5 4WT, United Kingdom

Single ion impacts have been observed using in-situ transmission electron microscopy during irradiation. In addition to internal defects, single-ion impacts create surface craters as large as $12 \mathrm{~nm}$ on $\mathrm{In}, \mathrm{Ag}, \mathrm{Pb}$ and $\mathrm{Au}$.

Crater formation rates have been determined from video recordings with a time-resolution of 33 milliseconds. The cratering rate for Xe ions increases linearly with increasing target mass density above a threshold density of approximately 7 $\mathrm{gm} / \mathrm{cm}^{3}$. The cratering rate increases as the ion mass is increased.

These results suggest that cratering requires a high energy-density, nearsurface displacement cascade. TRIM calculations have been made in an effort to establish a near-surface energy-density criterion for cratering.

\section{EXPERIMENTAL}

Ion irradiations were carried out at the IVEM/Accelerator Facility located at Argonne National Laboratory [1] in a Hitachi A-9000 transmission electron microscope (TEM) operating at $300 \mathrm{keV}$. The ion beam is oriented $30^{\circ}$ from the microscope axis, and all specimen were tilted $15^{\circ}$ towards the ion beam so that both ions and electrons were incident on the specimen at $15^{\circ}$ to the foil normal. Images from a Gatan 622 video camera and image-intensification system were recorded on video tape with a time resolution of a single video frame (1/30 s).

TEM Specimens of $\mathrm{AL}, \mathrm{Cu}, \mathrm{Ag}, \mathrm{In}, \mathrm{Pt}, \mathrm{Au}$ and $\mathrm{Pb}$ were produced from rolled, annealed foils with a 99.999 purity from which $3 \mathrm{~mm}$ discs were punched and electrochemically, thinned. In addition, thin Au films were made by thermal evaporation of 99.999 at \% pure starting material onto $\mathrm{NaCl}$ at a temperature of $350^{\circ} \mathrm{C}$. This resulted in a largely monocrystalline film with a $<100>$ surface normal. The gold films were determined by Rutherford backscattering to have a thickness of $62 \pm 2 \mathrm{~nm}$. The thickness of specimens fabricated from bulk material was not accurately known but was of the order of $100 \mathrm{~nm}$ or less.

Craters are made visible in TEM by means of their phase-contrast under controlled amounts of objective lens defocusing. Underfocussing the objective lens by 700 to $1000 \mathrm{~nm}$ yields images in which the crater is lighter than the background and is delineated by a dark Fresnel fringe. Similarly a small mound or particle on the surface appears darker than the background with a light fringe around it. In overfocus the contrast is reversed, i.e. small craters appear darker than the background and small particles appear lighter than the background.

Although atomic recoil from an ion impact occur on a time scale of picoseconds which can not be resolved using TV rate recordings, it is possible to separate impact events in time and distance so that the consequences of single 
impacts can be distinguished and analyzed. Typical ion fluxes used in this work result in a single ion impact each second in an area $30 \mathrm{~nm}$ on a side. During this time 30 video frames are recorded. Frame by frame examination is used to identify the sites of individual ion impacts.

\section{RESULTS}

We have examined many metals with transmission electron microscopy during in situ ion irradiation. Because of the ability to prepare very thin specimens with clean surfaces, most work has been on Au.

\section{Gold}

Holes production is the most spectacular event during ion bombardment of $\mathrm{Au}$ [2], however the most common event is the production by single ion impacts of -craters [3] as shown in figure 1 by images from single video frames. Craters are
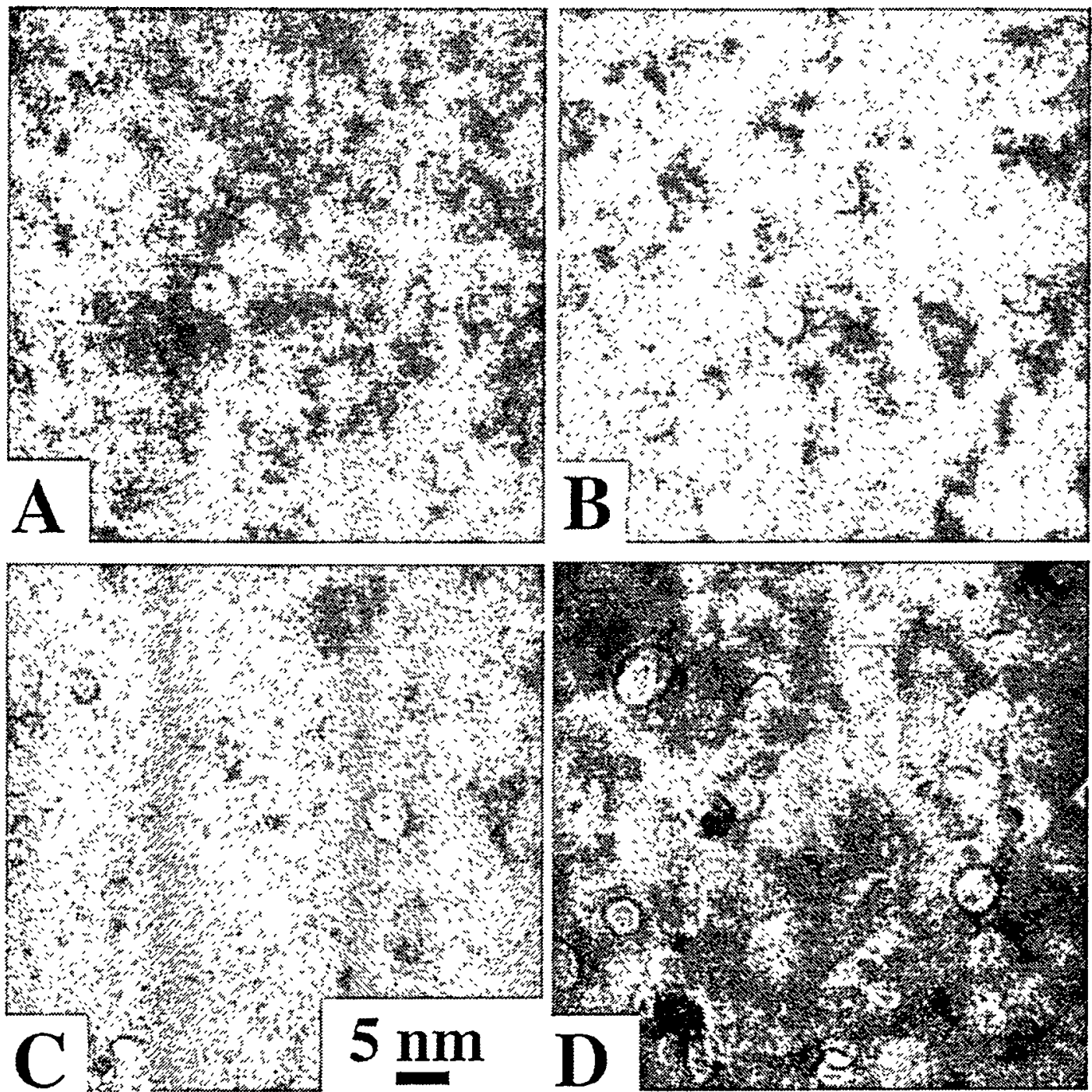

Figure 1 Au thin film irradiated at $300 \mathrm{~K}$ by (a) $200 \mathrm{keV} \mathrm{Kr}$ ions, (a) $200 \mathrm{keV} \mathrm{Xe}$ ions, (a) $200 \mathrm{keV} \mathrm{Au}$ ions, and (a) $400 \mathrm{keV} \mathrm{Au}$ ions. 
produced on $\mathrm{Au}$ by a range of ion masses and energies. Figure 1 shows examples of craters formed during irradiation with $\mathrm{Kr}, \mathrm{Xe}$ and $\mathrm{Au}$ ions. Also evident are ejected particles. The irradiations produced similar distributions of crater sizes and particle sizes. It is difficult to determine the number and sizes of craters produced by an ion from single images, and thus 10's of seconds of irradiation on 10 times this area have been used. In general, heavier mass ions produce more and larger craters than lighter mass ions. There are more small craters than large ones for all ion masses. These comparisons are affected by the ion energy deposition and range. As the energy of an ion is increased the probability for large energy deposition near the surface decreases and fewer craters are formed.

Craters are stable when the ion bean is interrupted, however during continued heavy ion irradiation, craters come and go. At the dose rates used in the ..experiments $\left(2.4 \times 10^{11}\right.$ ions $\left./ \mathrm{cm}^{2} / \mathrm{s}\right)$, on the order of 20 ions per second impact on the $110 \mathrm{~nm}$ by $85 \mathrm{~nm}$ area of the TV image. With crater creation rates of between 0.02 and 0.05 craters per ion on $\mathrm{Au}$, a new crater appears in the area viewed every 1 to 2 seconds. However, craters are unstable under irradiation and disappear as a result of other ion impacts. The impression is that of a fluid-like surface on which a crater (along with expelled material) suddenly appears and then disappears over several seconds, during which time new craters appear. However, frame-by-frame analysis reveals that crater creation and annihilation occurs in discrete steps.

In some cases crater annihilation is seen to occur as a consequence of plastic flow from a neighbouring impact site but in many cases the impact giving rise to annihilation or partial annihilation of a crater is not observed. Small craters, less than $2-3 \mathrm{~nm}$ in diameter, are generally annihilated in a single step. Assuming that all impinging ions may annihilate existing craters, the cross section for crater annihilation on gold irradiated with $200 \mathrm{keV}$ Xe ions is $85 \mathrm{~nm}^{2}$, i.e. an ion impact within a radius of approximately $5 \mathrm{~nm}$ of a small crater will annihilate the crater.

There can be significant transport of material from an ion impact site. Expelled material does not have the same shape as the crater from which it is ejected, implying that it has not been expelled as a solid particle. In many cases, the form of the expelled material indicates that molten material has been ejected from the melt zone of a cascade at the impact site and that surface tension has acted to produce forms ranging from an apparently quenched droplet to spherical particle. Macroscopic concepts such as melting, flow in response to surface tension forces, and quenching provide a satisfactory description of expelled material.

\section{OTHER MATERIALS}

In situ irradiations have been used to examine other materials for evidence of ion induced cratering. As with gold, craters are made visible using phase contrast by controlled defocusing of the objective lens. The specific details of cratering in 
these and other materials will be briefly discussed below. The materials are listed in order of atomic mass.

\section{Aluminum}

Cratering of $\mathrm{Al}$ has not been observed for irradiation by any single ion at any energy. On the basis of TRIM simulations [4], this is attributed to the inability of a ion impact to generate a sufficiently dense cascade in $\mathrm{Al}$ to create local melting. Without such a dense displacement cascade, cratering by flow does not occur.

\section{Copper}

A low cratering rate has been observed on $\mathrm{Cu}$ during $200 \mathrm{keV} \mathrm{Xe}$ irradiation at room temperature. The quality of the specimen surface has precluded accurate determination of the cratering rate, however it was low.

\section{Molybdenum}

Cratering of Mo has been detected during post irradiation observation by Jenkins, and Wilkens[5]. Measurement of cratering rate could not be made.

Silver

Cratering of $\mathrm{Ag}$ is qualitatively similar to that of gold The creation efficiency was determined to be $0.6 \%$ or almost an order of magnitude lower than for Au. The crater size distribution was broad with large irregular craters up to $10 \mathrm{~nm}$ in diameter. Craters filled in discretely as a result of subsequent ion impacts. Also, edges of the initial hole in the specimen underwent plastic flow.

\section{Indium}

Room temperature of In failed to reveal any cratering. Oxide was initially present on the indium surface as in the case of lead (see below) but even after examination of the diffraction pattern indicated that the oxide had been removed, cratering still did not occur. Since room temperature is $2 / 3$ of the melting-point of In, the absence of cratering at room temperature does not necessarily imply that craters did not form [6]. The existence of a crater for a sufficiently long period to be observed involves crater creation by spike induced local melting and flow and annealing by subsequent ion impacts and irradiation enhanced surface diffusion. Since the high homologous temperature may have resulted in a very rapid annealing of craters by surface and bulk diffusion processes as in the case of Au, indium was irradiated with $400 \mathrm{keV} \mathrm{Xe} \mathrm{X}^{+}$ions at $17 \mathrm{~K}$ using a cryogenic specimen holder in the TEM. A frame-by-frame analysis of the video recording of this experiment revealed the very occasional formation of craters at this temperature. These craters were observed to be annihilated in steps by subsequent ion impacts as was the case for the other metals.

\section{Platinum}

Catering was observed at room temperature for 100 and $200 \mathrm{keV} \mathrm{Xe} \mathrm{ions,}$ however as in the case of $\mathrm{Cu}$, it was not possible to prepare specimens with clean and adequately smooth surfaces. Thus the rate of cratering was not determined. 


\section{Lead}

Crater images in $\mathrm{Pb}$ were not as sharp as in the case of gold due to the higher degree of microscope defocus required to image the craters (The defocus used was typically $9 \mu \mathrm{m}$ underfocus c.f. $1 \mu \mathrm{m}$ for $\mathrm{Au}$ ). This indicates that the craters were shallower in this case than for Au. Also unlike gold there was little evidence of material ejected from the craters onto the specimen surface. The cratering rate on lead was approximately $0.7 \%$. As with $\mathrm{Au}$ and $\mathrm{Ag}$, the observed craters are thermally stable at room temperature when the ion irradiation is halted but under conditions of continual irradiation are annihilated discretely by subsequent ion impacts. The cross section for crater annihilation on $\mathrm{Pb}$ is approximately $85 \mathrm{~nm}^{2}$.

Initially an oxide layer on the $\mathrm{Pb}$ specimens suppressed cratering. No cratering was observed until a specimen had been bombarded with a dose of - $\quad$ approximately $4 \times 10^{14}$ ions $/ \mathrm{cm}^{2}$. Electron diffraction patterns from the specimen indicated that at lower doses an amorphous oxide layer was present on the surfaces of the specimen. At greater doses, the diffraction patterns revealed that the oxide layer had been removed by sputtering, and cratering began to occur. The implication of this observation is that cratering is suppressed if an oxide layer is present on the specimen. This is consistent with the finding by Merkle and Jäger [7] and us [3] that a thin amorphous layer of carbon deposited on gold films reduces the incidence of cratering on gold.

\section{COMPARISON Of MATERIALS}

Crater creation efficiency, $\varepsilon$ (craters per incident Xe ion expressed as a percentage), of the materials studied has been obtained by determining the number

of craters exist for at least a single video frame for a given time interval and is shown in figure 2 . The efficiency varies monotonically with atomic density rather

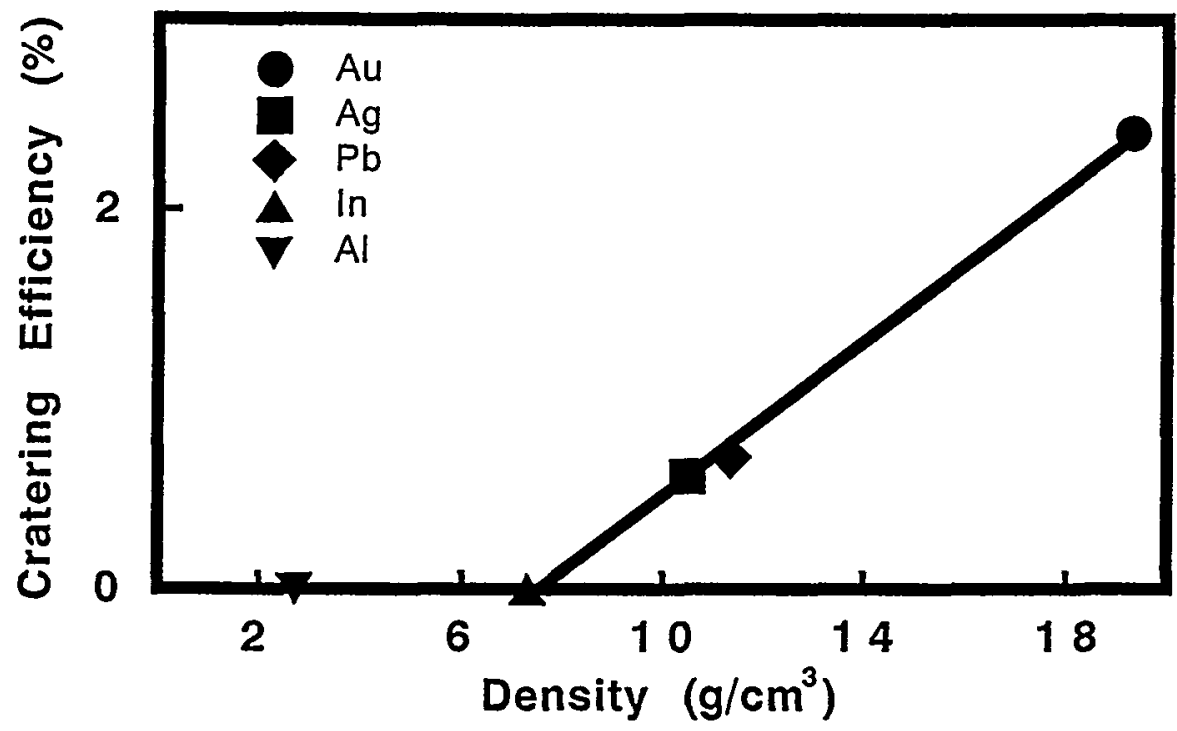

Figure 2 Cratering efficiency as a function of material density. The materials are indicated on the figure. 
than with atomic number, atomic weight or thermal conductivity. The figure indicates a threshold density for crater production (by Xe ions) of the order of the density of In; $7.3 \mathrm{gm} / \mathrm{cm}^{3}$. The necessary and sufficient condition for cratering to occur appears to be simply that atoms within a cascade close to the surface are given sufficient energy to cause melting [6]. MD modeling suggest that craters occur by a reflection of the cascade momentum back through the surface when there is a dense cascade that results in a melt zone [8]. The same processes are associated with holes production in very thin specimens. When the material density is to low to support dense cascades, neither craters or holes formed.

\section{SUMMARY}

The surface is a major perturbation on displacement cascades resulting from - ...ion impacts. Ion impacts on dense materials result in nanometer sized craters on materials with densities greater than $7.3 \mathrm{gm} / \mathrm{cm} 3$. Although stable when the irradiation is interrupted, single ion impacts can modify or annihilate existing craters. Single ion impacts can extrude material from the specimen. Flow from the melt zone of cascades is responsible for the observed changes.

\section{ACKNOWLEDGMENTS}

We thank B. Kestel for specimen preparation, R. E. Cook for assistance with analytical measurements and E. Ryan, L. Funk, P. Baldo, T MacCormack and S. Ockers for assistance with the in-situ TEM experiments. This work has been supported by the U.S. Department of Energy, BES-Materials Sciences, under Contract W-31-109-Eng-38 and by a collaborative research grant number 910670 from NATO. One of us (SED) acknowledges funding from the Materials Science Division at Argonne National Laboratory that enabled him to spend a sabbatical at ANL.

\section{REFERENCES}

1 C. W. Allen, L. L. Funk, E. A. Ryan and S. T. Ockers, Nucl. Inst. and Meth. B 40/41, 553, 1989.

2 R. C. Birtcher and S. E. Donnelly, Phys. Rev. Lett. 77, 4374, 1996.

3 S. E. Donnelly and R. C. Birtcher, Phys. Rev. $\underline{56}, 13599,1997$.

4 J. F. Ziegler, J. P. Biersack and U. Littmark, The Stopping and Ranges of Ions in Solids, (Pergamon Press, New York 1985).

5 M. L. Jenkins, and M. Wilkens, 1976, Phil. Mag. 34, 1155

6 S. E. Donnelly and R. C. Birtcher, to be published in Phil. Mag. 1998.

7 K. L. Merkle and W. Jâger, Phil. Mag, A44, 741, 1981.

8 R. S. Averback, M. Ghaly and H. Zhui, Mat. Res. Soc. Symp. Proc. Vol. 373, 3, 1995. 